\title{
Quando a Casa é a Marquise, o Albergue, a Rua: Discursos e Políticas Sociais para Pessoas em Situação de Rua em Belo Horizonte
}

\author{
When the House is the Sunroom, the Hostel, the Street: Discourses and Social Policies for Homeless People in Belo Horizonte \\ Cuando la Casa es la Marquesa, el Albergue, la Calle: Discursos y Políticas Sociales para Personas en Situación de Rua en Belo Horizonte \\ Bruno Eduardo Freitas Honorato \\ Doutorando em Administração / Universidade Federal de Minas Gerais - UFMG \\ Universidade Federal de Alfenas / Professor do Magistério Superior \\ http://lattes.cnpq.br/0918420069554526 \\ http://orcid.org/0000-0003-3670-0095 \\ brunoefh@gmail.com \\ Luiz Alex Silva Saraiva \\ Doutorado em Administração (concluído) / Universidade Federal de Minas Gerais - UFMG \\ Universidade Federal de Minas Gerais / Professor Adjunto da Faculdade de Ciências Econômicas \\ http://lattes.cnpq.br/8812184151373749 \\ http://orcid.org/0000-0001-5307-9750 \\ saraiva@face.ufmg.br
}

Resumo: A partir da constatação de que a população em situação de rua é uma questão social que precisa ser problematizada, nesse trabalho se busca compreender como são articulados discursos que subsidiam as políticas sociais para a população em situação de rua na cidade de Belo Horizonte. Considerada-se aqui a população em situação de rua como um grupo social relativamente coeso e minoritário em termos de poder político institucionalmente reconhecido. A partir de uma pesquisa qualitativa que se valeu de entrevistas semiestruturadas associada à observação participante e registro sistemático em diário de campo, foram obtidos subsídios relevantes para a abordagem da temática, material tratado por meio de análise do discurso. As principais categorias de análise concentraram nas pessoas em situação de rua e nas suas intenções, nos motivos que as levaram a residir nas ruas, no controle social e espacial, e na repressão a que estão sujeitos cotidianamente.

Palavras-chave: População em situação de rua; Políticas sociais; Discursos.

\begin{abstract}
Based on the verification that homeless people is a social issue that needs to be problematized, this work seeks to understand how the discourses that support social policies for the homeless people in the city of Belo Horizonte are articulated. It is considered here the homeless people as a relatively cohesive social group and minority in terms of institutionally recognized political power. From a qualitative research that made use of semi-structured interviews associated with participant observation and systematic recording in a field diary, relevant subsidies to approach the subject were obtained this material was analyzed through discourse analysis. The main categories of analysis focused on homeless people and on its intentions, the reasons that led them to live on the streets, in the social and spatial control, and repression to which they are daily subjected.
\end{abstract}

Key words: Homeless people; social policies; discourses.
Resumen: A partir de la constatación de que la población en situación de calle es una cuestión social que necesita ser problematizada, en ese trabajo se busca comprender cómo son articulados discursos que subsidian las políticas sociales para la población en situación de calle en la ciudad de Belo Horizonte. Se considera aquí la población en situación de calle como un grupo social relativamente cohesivo y minoritario en términos de poder político institucionalmente reconocido. A partir de una investigación cualitativa que se valió de entrevistas semiestructuradas asociada a la observación participante y registro sistemático en diario de campo, se obtuvieron subsidios relevantes para el abordaje de la temática, material tratado por medio del análisis del discurso. Las principales categorías de análisis se concentraron en las personas en situación de calle y en sus intenciones, en los motivos que las llevaron a residir en las calles, en el control social y espacial, y en la represión a que están sujetos cotidianamente.

Palabras clave: Población en situación de calle Políticas sociales; Discursos.

Texto completo em português: http://www.apgs.ufv.br Full text in Portuguese: http://www.apgs.ufv.b

\section{Introdução}

Quando Fraser (2007) discute as implicações das políticas de distribuição de renda e das políticas sociais de reconhecimento de grupos identitários para o modo de pensar da sociedade capitalista atual, traz contribuições de grande relevância para o entendimento da importância de se pensar os grupos minoritários hoje em dia. Para Fraser (2007), há um problema básico na ciência social que diz respeito à forma como se consideram as expectativas de resolução da diferença econômica entre as classes sociais e as expectativas dos grupos minoritários em relação ao reconhecimento da sua identidade, enquanto grupo, nas políticas sociais. O pensamento econômico tende a oferecer soluções de caráter essencialmente econômico, desconsiderando os aspectos culturais de reconhecimento e valorização desses grupos, enquanto em um paradigma cultural oferecem-se soluções de amparo e fortalecimento das culturas chamadas "desviantes" da sociedade "normal". O desafio para esse autor seria superar a presente dissociação dos modos de pensar econômico e cultural, devendo ser corrigida tanto a tendência atual de substituir um paradigma inacabado pelo outro, um culturalismo inacabado por um economicismo inacabado, quanto corrigir a tendência de substituir as inacabadas políticas sociais de reconhecimento por inacabadas políticas econômicas de redistribuição. Os dois níveis se interpenetram para além disso.

Reivindicações por redistribuição buscam uma distribuição mais justa de recursos e riquezas, enquanto reivindicações de reconhecimento, com maior respeito às diferenças intergrupais. $A$ dificuldade encontrada é justamente a conciliação de políticas que 
efetivamente proporcionem uma distribuição de renda adequada aos grupos tidos como inferiores, bem como a adequação de políticas sociais que atendam ao interesse desses grupos de maneira que confronte diretamente a discriminação, a exclusão social e a despolitização dos interesses de tais grupos.

Para Fraser (2007), a falta de uma política efetiva de distribuição de renda leva necessariamente a uma política de não reconhecimento das características identitárias de grupos minoritários. Tanto quanto, a falta de reconhecimento dos interesses desses grupos também acarreta a não institucionalização de mecanismos políticos e econômicos que possam atender às suas necessidades. $\mathrm{A}$ ideia de que há uma hierarquia entre classes sociais, no sentido de classes econômicas, e entre o status social, grupos identitários divididos, se deve a corroboração de discursos que privilegiam os grupos que detém, hoje, não apenas a capacidade de normatizar os padrões culturais, bem como a capacidade de estabelecer os mecanismos econômicos e políticos que façam perpetuar seu status na sociedade.

No que tange à população em situação de rua, esses mecanismos econômicos e políticos que permitam sua expressão e a luta por direitos enquanto grupo, são escassos. Vários autores têm questionado essa situação, especialmente no campo do reconhecimento dos direitos das pessoas em situação de rua, em que se a há um descontentamento dos grupos de defesa dos direitos humanos, bem como das organizações religiosas e das ONGs que tratam diretamente com esta população. Fóruns temáticos populares e comitês de formação de políticas públicas para essa população têm constituído, ainda que localmente e de maneira bastante incipiente, os novos espaços institucionais a que tem acesso pessoas em situação de rua engajadas na luta política e na discussão de direitos sociais dessa população. Espaços novos, dada a longa trajetória dessa população pelas cidades, historicamente remetida ao êxodo rural e ao processo de urbanização (Bursztyn, 2003).

A questão do reconhecimento desse grupo, enquanto um grupo de direitos e deveres, passa pela discussão dos discursos que legitimam a miséria nas sociedades contemporâneas (Resende, 2008). Discursos que são extraídos em diversas fontes, têm efeitos ideológicos imediatos, e contribuem, muita vez, para a manutenção da injustiça social. A precariedade das condições de vida dessa população e a negação dos seus direitos, enquanto grupo, estão no cerne da questão da justiça social. As justificativas que se dão à perda do "sentimento de semelhança" e do juízo ético que faz com que os seres humanos sintam-se parte de uma mesma espécie estão explícitos em construções sociodiscursivas que naturalizam a miséria como um fenômeno social se não justo, pelo menos, aceitável socialmente.

À parte disso, a população em situação de rua dispõe de recursos políticos escassos para a concretização de políticas sociais que sustentem uma mudança imediata na forma como são tratados enquanto grupo. As iniciativas são locais, muitas vezes religiosas, e alcançam paulatinamente um crescimento em nível municipal, mas que se defronta em vários níveis com a falta de acesso e com a carência de recursos, dada as prioridades do Estado. Ainda considerando a complexidade que envolve o tratamento dessa população e as dificuldades que se entrelaçam, confrontando a possibilidade de reconhecimento desse grupo e os efeitos sociais da sua existência na sociedade atual, nesse trabalho, questionamos basicamente os discursos que envolvem a criação das políticas públicas que dão amparo e sustentação a lida com essa população na gestão municipal de Belo Horizonte, locus em que essa pesquisa foi realizada.

Considerando esses pontos iniciais, nesse trabalho se busca compreender como são articulados discursos que subsidiam as políticas sociais para a população em situação de rua na cidade de Belo Horizonte, considerada aqui como grupo social relativamente coeso e minoritário em termos de poder político institucionalmente reconhecido. Para tanto, nas duas seções teóricas subsequentes, buscamos uma aproximação teórica com a população em situação de rua no Brasil e examinamos as caracterizações e tipificações desta população. Em seguida apresentamos os aspectos metodológicos do estudo, que precedem a análise dos dados e a última seção, de discussão e considerações finais.

\section{População em situação de rua no Brasil}

A população em situação de rua tem sido estudada por vários autores de áreas diversas (Costa, 2005; Ghirardi, Lopes, Barros, \& Galvani, 2005; F. P. M. Ferreira \& Machado, 2007; Varanda \& Adorno, 2004; Magni, 2010; J. Ferreira, 2006; J. Ferreira, 2010; Neves, 2010) e embora as visões muitas vezes sejam destoantes, há um consenso de que as políticas sociais no Brasil ainda não conseguem estabelecer uma proposta que atenda às reais necessidades dessas pessoas. Costa (2005, p. 10) afirma que "o desafio está em elaborar alternativas que possam adequar-se à realidade de quem vive nas ruas, especialmente que levem em conta o estágio em que as pessoas se encontram".

A Política Nacional de Inclusão Social da População em Situação de Rua, Decreto $s / n$ (2008), é atualmente a principal referência em âmbito nacional para orientar a construção e execução de políticas públicas para a população em situação de rua no Brasil. Traçada pelo Grupo de Trabalho Interministerial para Elaboração da Política Nacional de Inclusão Social da População em Situação de Rua e instuída em 25 de junho de 2006 a referida política é resultado dos debates e reflexões dos representantes dos Ministérios do Desenvolvimento Social e Combate à Fome; das Cidades; da Educação; da Cultura; da Saúde; do Trabalho e Emprego; da Justiça; da Secretaria Especial de Direitos Humanos e Defensoria Pública da União, além dos representantes do Movimento Nacional de População de Rua (MNPR), da Pastoral do Povo da Rua e do Colegiado Nacional dos Gestores Municipais da Assistência Social (CONGEMAS), representando a sociedade civil organizada. A referência de uma política nacional para construção de políticas sociais em âmbito municipal ampliam a possibilidade de 
discussão nos eixos temáticos dos fóruns populares dedicados à população em situação de rua nos municípios.

A instituição da Política Nacional de Inclusão Social da População em Situação de Rua e da Política Nacional para a População em Situação de Rua instituída em 23 de dezembro de 2009, têm possibilitado visibilidade para o grupo historicamente marginalizado nas prioridades dos poderes públicos. A identificação dos aspectos identitários que localizam a população em situação de rua como um grupo populacional heterogêneo é uma das principais preocupações das políticas supracitadas. A identificação das pessoas em situação de rua nos espaços, a forma como ocupam a cidade, o tempo de ocupação e o entendimento da maneira como lidam com a vida na rua permitem compreender melhor a desigualdade social brasileira e o estigma que caracteriza os não domiciliados. Em relação às políticas sociais e, principalmente, a participação de pessoas em situação de rua e ex-moradores de rua na discussão dos temas referentes a essa população, Melo (2015, p. 199) que acompanhou as atividades do Movimento Nacional da População de Rua desde 2009, afirma que, em relação ao decreto que institui a Política Nacional para Pessoas em Situação de Rua,

um dos resultados que (...) chamou atenção foi o fortalecimento político de pessoas que se reconhecem enquanto população de rua, que passam a fazer parte ativa dessa rede e que começam a atuar no MNPR, principal núcleo aglutinador de proposições no plano da ação pública por parte do segmento

O MNPR, como um movimento social lançado publicamente em 2005, é fruto da politização em torno da questão da "população de rua" que ganhou força na década de noventa com um intenso processo de luta por reconhecimento e que resulta na constituição de manifestações, fóruns, seminários, encontros e demais espaços específicos para a organização dessa população (Melo, 2015).

A população em situação de rua foi praticamente excluída das políticas brasileiras até a década de noventa. Entretanto a luta pelos direitos dessa população já acontecia há algum tempo, mostrando contornos desde 1950 na cidade de São Paulo (Melo, 2015). A consolidação das políticas enquanto texto manifesta uma prática discursiva importante para a população em situação de rua, em termos de direitos previstos na constituição brasileira.

A participação dos diferentes segmentos da sociedade na formulação das políticas, inclusive da própria população em situação de rua pela representação do MNPR, indica uma possibilidade de apropriação das demandas sociais por meio dos debates, como afirma Decreto $\mathrm{s} / \mathrm{n}$ (2008, p.2),

a consolidação das idéias inseridas neste Documento percorre um processo necessário de discussão de seu texto nos diversos fóruns de debate de políticas públicas sociais, de forma a permitir a mais ampla participação de diferentes segmentos da sociedade.

Os problemas relacionados à utilização da cidade pelas pessoas em situação de rua e os confrontos com a população domiciliada, colocam a administração pública municipal em uma posição de mediadora, ao mesmo tempo em que se situa como produtora e mantenedora da ordem social também possibilita a ação de agentes engajados na transformação das práticas discursivas relacionadas à população em situação de rua.

Em Belo Horizonte o Decreto 14.146 (2015) de 07 de outubro de 2010 institui o Comitê de Acompanhamento e Monitoramento da
Política Municipal para a População em Situação de Rua responsável por acompanhar, assessorar e monitorar a política voltada para a população em situação de rua. São doze representantes do poder público e doze representantes da sociedade civil. Sendo que dos doze representantes titulares e suplentes da sociedade civil são eleitos cinco representantes da população em situação de rua organizada, por meio de movimentos sociais, fóruns e comissões de usuários de serviços; um representante de instituições acadêmicas e de pesquisa; dois representantes de instituições prestadoras de serviços voltados para o atendimento da população em situação de rua; três representantes de instituições de assessoramento e defesa dos direitos da população em situação de rua; um representante de outras entidades, instituições, organizações e associações interessadas em contribuir para o fortalecimento da Política Municipal para População em Situação de Rua.

As respostas que são dadas à existência dessas populações, consideradas ociosas, têm sido, por vezes, "medicalizantes" sentido de "reduzir a dimensão de um problema social complexo a um diagnóstico médico clínico, ou entendê-la na dimensão dos preceitos higienistas e sanitaristas, na ótica da remoção das populações em circulação pelas cidades" (Adorno \& Varanda, 2004, p. 57), ou proibitivas (Nardi \& Rigoni, 2005, p. 275), no sentido de não permitir manifestações que tenham visibilidade negativa diante desse regime, tal como no caso dos usuários de drogas (ilícitas, principalmente). Embora disponibilize, também, organizações que amparam essas populações, como albergues, repúblicas, casas de recuperação, essas organizações no Brasil são, em sua maioria, fundadas e mantidas por órgãos religiosos e por entidades caritativas (Costa, 2005; Mendes, 2007; 2010).

Por outro lado, em alguns casos, os agentes municipais, têm adotado uma proposta de redução de danos. Baseada na criação de vínculo entre agentes sociais e populações vulneráveis, a partir de um método de atuação não proibitivo, a fim de reduzir os agravantes de risco de saúde nas práticas cotidianas dessas populações (Nardi \& Rigoni, 2005). Em princípio, a redução de danos,

pode ser definida como um conjunto de medidas em saúde que tem a finalidade de minimizar as consequências adversas do uso/abuso de drogas. Tais ações possuem como princípio fundamental o respeito à "liberdade de escolha" (Nardi \& Rigoni; 2005, p. 274).

Embora, hoje, as técnicas que foram desenvolvidas para tratamento de usuários de drogas também sejam utilizadas em uma perspectiva de saúde pública para as pessoas em situação de rua. A noção de redução é baseada em políticas de desestimulo do uso abusivo do álcool e de drogas ilícitas. No Brasil, a redução de danos tem seus primeiros empreendimentos realizados em São Paulo, em 1989, e somente a partir de 1995 foi permitido que algumas técnicas fossem realizadas legalmente (Nardi \& Rigoni; 2005). A principal característica que constitui as políticas de redução de danos é o pressuposto de que o usuário, ou no caso, a pessoa em situação de rua, é livre para agir da maneira que bem entender. Isso influi diretamente no tratamento "sempre respeitando o momento e a vontade do usuário" (Nardi \& Rigoni, 2005, p. 275). O respeito e o 
trato com a população de rua, bem como com as populações vulneráveis, pode ser diferencial na formação de vinculo, e, por conseguinte, na abertura de novas possibilidades essas populações.

Apesar disso, a política de redução de danos ainda é incipiente, tem sido adotada em vários âmbitos de tratamento com populações vulneráveis. De maneira geral, as políticas públicas encontram dificuldades para o tratamento dessa população dada a sua alta complexidade. Muitas vezes, a falta de endereço fixo corrobora para a dificuldade de acesso a hospitais, postos de saúde, para colocar os filhos na escola etc. Além disso, falta de documentação é um problema que atinge ampla parte dessa população e dificulta 0 acesso aos serviços públicos (Resende, 2008).

\section{Caracterizações e tipificações da população em situação de rua}

Direta ou indiretamente, não são poucos os autores que passam por caracterizações ou tipificações das pessoas em situação de rua em seus estudos (Ghirardi, Lopes, Barros, \& Galvani, 2005; Costa, 2005; Silva, 2010; C. Ferreira \& Machado, 2007; Mendes, 2007; Mendes \& Cavedon, 2012; Snow \& Anderson, 1998). Recentemente o governo brasileiro também resolveu definir essa população com a proposição de melhor entendê-la para criar políticas públicas mais eficazes no que tange à sua condição. No Decreto de $n^{\circ} \mathbf{7 . 0 5 3}$, de 23 de dezembro de 2009, o governo brasileiro definiu como pessoas em situação de rua como:

o grupo populacional heterogêneo que possui em comum a pobreza extrema, os vínculos familiares interrompidos ou fragilizados e a inexistência de moradia convencional regular, e que utiliza os logradouros públicos e as áreas degradadas como espaço de moradia e de sustento, de forma temporária ou permanente, bem como as unidades de acolhimento para pernoite temporário ou como moradia provisória (Decreto ํㅜㄱ.053, 2009)

Caracterizações e tipificações são importantes porque influenciam como as pessoas agem e pensam sobre uma situação. "Ser" da rua e "estar em situação" de rua remetem diretamente a formas diferentes de tratamento desses sujeitos. A passagem da nomenclatura "mendigo" ou "pedinte" para "pessoas em situação de rua" no Brasil. Sobre isso, Neves (2010) nos conta que o termo "população em situação de rua" foi cunhado pelos agentes sociais que se voltam para o apoio institucional ou para a intervenção estatal, buscando superar estigmas ligados à nomenclatura do "mendigo" relacionada diretamente com a vagabundagem e com a preguiça.

O entendimento do termo população em situação de rua, enquanto um termo que reflete uma condição de instabilidade, almeja dar conta da fragmentação e da multiplicidade de experiências que envolvem essa população como um todo (Silva, 2010). Muitos se movem entre cidades, outros se movem dentro da cidade e uma parte tem casa, mas preferem a rua nos finais de semana (Mendes, 2007). Não apenas pela velocidade em que essa população se forma e se dispersa - por meio dos viajantes e das pessoas que ficam nas ruas por pouco tempo - mas também pela mobilidade de relações entre seus componentes, o termo situação de rua se tornou mais adequado. A população de rua é instável em toda a sua amplitude, tendo como característica principal a vida em uma condição que não possibilita acumulações de qualquer tipo (Mendes, 2007; Silva, 2010).

Neves (2010, p. 103) se empenha em trabalhar o conceito de mendicância sob o caráter do "trabalhador que não deu certo", partindo de uma análise sociológica das causas estruturais da condição de rua. Para ela, "a mendicância como fenômeno social" poderia "ser estudada a partir de formas de reprodução social da massa trabalhadora". O que ela quer dizer com isso é de que forma a sociologia poderia contribuir para a compreensão dos modos de vida dessa população e das experiências inerentes a essa condição. Outra abordagem é a de Costa (2005), que escreve justamente pensando em caracterizações e contextualizações para a população em situação de rua do Brasil à luz da assistência social. Partindo de autores como Bauman e Castel, Costa (2005) descreve a situação de rua como um dos processos resultantes da intensa fragmentação em que vive a sociedade atual. Para ela, a condição de rua é uma extrapolação da fragmentação social de um Estado que se tornou flexível pelas exigências do capital.

Também os norte-americanos Snow e Anderson (1998) caracterizaram a população em situação de rua. Para eles essa população forma uma subcultura em meio à cultura tradicional do país. A proposta desses autores aponta para a situação de rua enquanto um estilo de vida que muitos dos moradores de rua americanos adotaram durante algum período de suas vidas, por uma escolha voluntária ou não. Snow e Anderson (1998) reforçam as características que fazem com que os moradores de Rua de Austin, no Texas, se deparam ao se encontrarem nessa condição pela primeira vez.

As tipificações, aqui entendidas como classificações da vida de rua nos seus diferentes aspectos, são empreendidas por autores brasileiros (Mendes, 2007; Vieira, Bezerra \& Rosa, 1994) e pelos norte-americanos Snow e Anderson (1998). Em Belo Horizonte, Mendes (2007) trabalhou em uma tipificação dos moradores de rua a partir de uma observação quanto à forma como eles mesmos se tratam. Algumas das nomenclaturas usadas pela autora podem ser generalizadas e comparadas em nível nacional, porque fazem parte do discurso inscrito no meio em que trafegam os moradores de rua de todo o país. Nomes como maloqueiros, caídos, migrantes, trabalhadores itinerantes e trecheiros fazem parte das formas de identificação definidas pela trajetória de vida de cada uma das pessoas que caíram nas ruas.

No que se referem às tipificações feitas por pesquisadores norte-americanos, Snow e Anderson (1998), na primeira parte do seu trabalho, procuram mostrar quem são e como são vistos aqueles moradores de Rua de Austin que estudaram. Dessa busca, nasce uma tipificação baseada tanto nas denominações dos próprios moradores sobre si mesmos, quanto nas denominações dadas a eles historicamente pela sociedade norte-americana. Recém-deslocados, vacilantes regulares ou adaptados, andarilhos tradicionais ou hippies, mendigos tradicionais, mendigos redneck e 
doentes mentais constituem o quadro da tipologia social identificada pelos autores. Essa classificação tem uma base identitária que se desenvolve na medida em que o desafortunado (como sugerem os autores) aceita sua condição de rua e se adaptada ao discurso instituído nela.

\section{Aspectos metodológicos}

Oriundo de uma pesquisa originalmente direcionada a uma dissertação de mestrado, este artigo se vale do método da observação participante em conjunto com entrevistas semiestruturadas (Angrosino, 2009). A observação participante envolveu o acompanhamento de uma equipe religiosa em sua atividade de auxílio às pessoas em situação de rua na cidade de Belo Horizonte durante três meses. As entrevistas foram feitas logo após esse período considerando os diversos atores que participam da construção das políticas sociais para pessoas em situação de rua em Belo Horizonte. Foram entrevistados nove sujeitos com perfis variados reconhecendo que os discursos dos diferentes atores lutam por legitimidade nas instâncias de construção textual das leis.

Neste trabalho, apesar de reconhecermos as perspectivas correntes sobre a Análise do Discurso, optamos pelo entendimento de discurso e sua análise a partir da contribuição de Fairclough (2001). Entende-se que os atores reproduzem os discursos sociais na medida de seus interesses e compreensão sobre a questão da vida de rua. O discurso é uma prática, esteja ela orientada para a construção de textos ou não. O que se toma por texto, aqui, é, portanto, um produto dos discursos. O texto, tanto quanto a fala, têm fundamentação ideológica. A construção de falas indica uma prática socialmente estruturada e estruturante. Apesar, da análise do discurso não se prender ao texto e às falas, a produção de textos é um elemento especialmente importante para institucionalização de determinadas práticas. Um texto pode ser uma lei, formalmente publicada, ou uma fala informal numa mesa de bar. A linguagem, enquanto instancia de criação e transformação de estrutura social, parte da noção de significados partilhados dentro dessa estrutura.

Para Fairclough (2001) a noção de texto é importante, porque um texto sempre possui significados extraídos de outros textos, isto é, o termo intertextualidade evoca a noção de que um texto dentro de outro texto. O termo interdiscursividade é utilizado para distinguir discursos que se relacionam semanticamente com outros discursos, isto é, compartilham significados. Os significados estão sempre em luta para garantir sua legitimidade. A noção de hegemonia se dá a partir da garantia plena de legitimidade para um ou alguns significados que determinam outros.

No albergue foram abordados o gestor geral (código E1), a coordenadora de assistência social (E2), por ser o albergue, representado pelo Grupo O Consolador em Belo Horizonte, um das entidades que indica os representantes da sociedade civil no Comitê de Acompanhamento e Monitoramento da Política Municipal para a População em Situação de Rua.

Duas pessoas em situação de rua (PSR1 e PSR2) representando a população em situação de rua que frequenta o albergue. Os relatos das pessoas em situação de rua encontradas nas ruas durante a observação participante foram colhidos e analisados juntamente com as entrevistas subsidiando ou confrontando os depoimentos dos entrevistados.

$\mathrm{Na}$ Secretaria de Políticas Sociais de Belo Horizonte foi entrevistada a Assessora de Gabinete, Presidente do Comitê de Acompanhamento e Monitoramento da Política Municipal para a População em Situação de Rua (E3). Sendo a principal representante do Comitê nas entrevistas, porque presidenta, e portadora de uma posição social de destaque em relação à questão da população de rua na cidade de Belo Horizonte, uma vez que tem acesso aos canais institucionais de legitimação das práticas sociais permitidas ou não a essa população.

$\mathrm{Na}$ ONG Aliança de Misericórdia foi entrevistado o responsável pelo projeto em Belo Horizonte (E4).

Também foi entrevistado o técnico mais antigo da prefeitura envolvido com o tema (E5). E5 presenciou todo o movimento de mudança desde os anos noventa até a instituição do decreto de 2009 e participou ativamente na construção do Fórum de População de Rua de Belo Horizonte, o qual à época da pesquisa ainda funcionava na Pastoral de Rua do município.

No Centro de Referência em População de Rua foi entrevistado o Coordenador (E6), e na República Maria Maria, a gestora geral (E7), como dois representantes da atuação municipal descentralizada de Belo Horizonte.

Foram coletados relatos dos sujeitos da pesquisa durante a observação participante que vieram a somar-se aos dados da observação e das entrevistas, possibilitando fontes de informação que se complementaram enquanto construção de uma dada realidade. A base que sustenta a opção epistemológica e metodológica desse trabalho se alinha com a proposição de Gonzalez Rey (2009) para uma pesquisa construtiva-interpretativa de natureza qualitativa.

Os dados foram trabalhados mediante a proposta teóricometodológica da análise do discurso inspirada na proposta de Fairclough (2001). Dos métodos e técnicas de pesquisa utilizada, houve uma congruência que tornou possível a compreensão do fenômeno população em situação de rua em níveis pessoal, organizacional e municipal. A intenção da pesquisa foi captar os diferentes discursos dos atores sociais envolvidos na situação de rua e contrapô-los diante tanto da perspectiva subjetiva do observador, quanto de um método de análise do discurso. Portanto, as observações realizadas em conjunto com as entrevistas e a análise dos dados foram suficientes para que as considerações finais deste trabalho fossem elaboradas, ainda que não seja uma pesquisa exaustiva sobre o tema e especialmente sobre os sujeitos em situação de rua. Apesar das limitações de cada método, por meio da triangulação, suas contribuições foram mais bem compreendidas e possibilitaram as conclusões sugeridas para o estudo.

$\mathrm{Na}$ análise do discurso partimos da identificação e análise dos elementos lingüísticos para situar aspectos ideológicos na construção do discurso dos atores e seus efeitos constitutivos sobre os aspectos identitários da população em situação de rua e sobre as relações sociais em que eles se imergem. Para isso nos valemos 
a) da análise lexical; b) dos temas e figuras (explícitos ou implícitos) dos discursos, inclusive os personagens; c) dos percursos semânticos estruturados a partir dos temas e figuras; d) dos aspectos interdiscursivos; e) dos aspectos refletidos e refratados nos discursos; f) das condições sociais de produção dos discursos; g) dos discursos presentes no texto; h) dos aspectos ideológicos defendidos e combatidos nesses discursos; e i) da posição do texto em relação ao discurso hegemônico na sociedade em que se situa; inspirados na sistematização de Saraiva (2009), para, enfim, destacar os significados compartilhados socialmente em determinados grupos, enquanto estratégias discursivas de persuasão, que detém força política de atuação institucional segundo a posição dos atores que têm direito a fala nessas instâncias. Cabe esclarecer que nos valemos de uma sistematização para a análise do discurso, baseada majoritariamente em elementos lingüísticos, mas entendemos com Fairclough (2001) o discurso como uma prática social reprodutora e transformadora de realidades sociais e a possibilidade de um sujeito social que contesta e reestrutura a dominação e as formações ideológicas socialmente empreendidas; uma vez que ora ele se conforma às formações discursivas/sociais que o compõem, ora resiste a elas, reconfigurando-as ou ressignificando-as. Nesse sentido, a base epistemológica do nosso estudo é fundada na possibilidade da mudança social a partir de uma mudança nos discursos que operam a legitimidade dos significados construídos socialmente.

\section{Análise dos dados}

Emergiram do tratamento do material coletado seis categorias discursivas: a) "Trecheiros" e migrantes: o controle das intenções; b) A mudança da população em situação de rua; c) O esforço por uma dignidade "perdida": o controle legal no uso da cidade; d) Repressão policial e repressão social; e) Os limites fugidios da população em situação de rua; e f) "Necessidades na porta da minha casa?", a seguir detalhadas.

\section{"Trecheiros" e migrantes: o controle das intenções}

No fragmento (001) aparecem as figuras dos "trecheiros" e dos migrantes, as quais o enunciador associa a normas para frequentar 0 albergue.

(001) Tem alguns benefícios tem bagageiro ele pode deixar a bagagem até o outro dia e tem um almoço que é liberado então o migrante no município ele tem essa acolhida diferenciada, mas aí... Ele tem que estar documentado ele tem que vim realmente a procura de trabalho e aparece muito trecheiro, pessoa que ta passeando em Belo Horizonte ta aqui à procura de um tratamento de saúde, e no caso para tratamento de saúde a gente abre, tem que procurar o próprio município e....as vezes fica demandando vaga na população de rua, na ala dos migrantes e a gente não tem ai o pessoal sai procurando em todos os equipamentos da defensoria publica, tudo ai, para poder ver se consegue vaga. (E2)

No fragmento (001) dois personagens são explicitamente mencionados, o "migrante" e o "trecheiro". Conforme Mendes (2007) cada um deles tem traços específicos de movimentação na cidade. Entre migrantes e trabalhadores itinerantes estão os que deixaram suas cidades em busca de um trabalho ou de uma vida melhor em Belo Horizonte e, depois de frustrações sucessivas, buscam seu sustento nas ruas enquanto não encontram oportunidade e dinheiro para voltar a suas cidades natais. Trecheiros são os que vivem do trecho, das viagens e da mendicância nas estradas.

Um percurso semântico de "controle das intenções" surge na seleção lexical "tem que vim realmente à procura de trabalho" que são aspectos condicionantes para o uso do albergue. Num recorte de tempo e espaço, o fato de "ter" que vir a procura de trabalho, assume a condição de uma estratégia (Certeau, 1998) de organização das posições dentro do albergue. Aqueles que não têm intenção de trabalhar são barrados, não podendo usufruir o lugar. Ora, subentende-se que não o merecem, que suas "intenções" são alheias à vontade do Estado. Nesse sentido, no albergue se organiza e estabelece um poder, ao se ditar as regras, e filtrar quem deve ou não deve ali estar. Nesse sentido há uma relação direta entre os significados traçados pelo percurso semântico extraído da fala e a construção das políticas sociais para as pessoas em situação de rua, dado que o argumento de que seja necessária uma intenção de "vir em busca de trabalho" dispõe sobre quem deve ou não ser acolhido pelas políticas sociais remetidas a essa população. Os significados estão sempre em jogo e os discursos em constante luta por legitimidade (Fairclough, 2001), o que estabelece uma relação de força e posiciona os sujeitos, no caso, as pessoas em situação de rua como sujeitos sociais que dependem de recursos do Estado.

Há um interdiscurso entre "trabalho" e "merecimento", que se refere ao uso do albergue, o qual privilegia àquele que busca trabalhar, em detrimento daquele que está apenas "de passagem" pela cidade. Esse discurso se alinha ao que é valorizado socialmente na relação entre trabalho e dignidade. Importante notar que essa posição meritocrática, especialmente incorporada pela classe média brasileira (Chauí, 1989), defende o trabalho como forma exclusiva de merecimento da cidadania, desconsiderando as histórias de cada indivíduo e que o levaram a optar por caminhos alternativos de existência. Pelo fato de ser um grupo relativamente grande de trecheiros e de migrantes que caminham pelo país, seja em busca de trabalho ou não, suas peculiaridades deveriam ser consideradas na construção de políticas públicas, ainda que, enquanto particularidades de grupo, a despeito do que acontece e do que se tenta justificar (e de fato se legitima socialmente) pelo discurso da meritocracia.

\section{A mudança da população em situação de rua}

No fragmento (002) são discutidas as questões de mudança do perfil das pessoas em situação de rua, como se deu essa mudança e qual é o perfil dessa população hoje.

(002) Eu acho que é multifatorial, mas a questão social ela é gritante sim, vou te dar um exemplo, antigamente aqui o nosso publico a maioria era de pessoas que vinha do interior, então ainda tinha muito aquela questão assim: "eu vou para Belo Horizonte para tentar trabalhar" chegando aqui a pessoa não encontrava emprego ia para 
rua entende? Esse público hoje mudou. Nosso publico hoje é um publico mais jovem, maioria é da região metropolitana... Então são jovens que tiveram ali uma questão com a droga, ou com o trafico de drogas, entende? E vem para rua, ai você pergunta o que ta na origem disso é só a droga, eu acho que não é a desigualdade social mesmo, as vezes, é uma pessoa que não teve acesso a uma escola adequada entende? (E7)

No fragmento (002), o enunciador evoca o termo "antigamente" para ressaltar, interdiscursivamente, aspectos que diferenciam o passado do presente. Segundo ele, no passado, a população em situação de rua que frequentava a organização de amparo era diferente da de hoje. Há um implícito subentendido de que o desemprego ou a falta de condições de trabalho era a grande causa da situação de rua. Hoje, entretanto, a grande maioria, vai para as ruas por causa das drogas, que levam as pessoas a morarem na rua.

Um percurso semântico possível é o da "mudança do perfil das pessoas em situação de rua" apesar de sua manutenção - da situação de rua ao longo da historia - enquanto fato social. O principal aspecto defendido pelo discurso é o de que a população de rua não é a mesma daquela que vinha para as ruas no passado. É importante notar as conotações ideológicas que esse discurso pode assumir como forma de recriminação dessa população quando fundida à questão das drogas, tom moralista. $\mathrm{O}$ uso desse discurso para justificar uma internação compulsória vem sendo questionado pelas práticas de várias cidades brasileiras, especialmente no Rio de Janeiro e em São Paulo (Silveira, 2013). O enquadramento da população de rua como "crackeados" implica uma estratégia discursiva que possibilita a coerção, a imposição de uma ordem social e um controle pela limpeza social. Portanto, cabe uma análise criteriosa, inclusive sob um percurso semântico do "controle pela estigmatização" dessa população, uma vez que não é possível generalizar e naturalizar que todas essas pessoas usam drogas, ainda que elas façam parte do cotidiano de muitas delas. A tentativa de estigmatizar a população em situação de rua também é inibidora no sentido de privar essa população de uma ação política, dado que usuários de drogas, em geral, são marginalizados como incapazes de cuidar de seus deveres e direitos individuais. No âmbito das políticas sociais, a manutenção de um discurso como esse, generaliza e estigmatiza a população em situação de rua, o que prejudica nas suas possibilidades de atuação institucional para realizar os próprios direitos.

O esforço por uma dignidade "perdida": o controle legal no uso da cidade

No fragmento (003) o enunciador situa a política de intervenção da prefeitura em relação às práticas da população em situação de rua. Há uma menção ao código de posturas de município e também ao argumento da dignidade humana frente às condições de rua.

(003) Isso que dizer que: se um sujeito seja ele em situação de rua ou não, resolver montar uma barraca com tapume na rua no espaço público, colocar ali um colchão, que muitas vezes ele ganha da própria sociedade civil, que depois liga para o município fala: "aqui tem um sujeito com um colchão aqui na minha rua" quem deu o colchão para ele? Colocar ali um fogareiro, começa a cozinhar, lavar suas roupas, montar ali um varalzinho para secar, o município tem que intervir, isso tá previsto inclusive no código de postura do município, faz parte do parecer classificado da procuradoria geral e nesse sentido a área de fiscalização do município junto com a área social vai abordar esse sujeito dizer: "você não pode fazer isso que você esta fazendo aqui" e vai recolher, é uma questão... é um limite tênue é... tem demandado da gente um esforço muito grande no sentido de conversar com a pessoa que estar na em situação de rua, também com a sociedade pra não ofertar esse tipo de instrumental para ele se estabelecer na rua, porque nos não podemos reconhecer o direito de viver na rua, viver na rua não é digno para ninguém... (E3)

O enunciador do fragmento (003) se opõe a qualquer suporte social para que viver nas ruas possa ser, de alguma forma, “confortável”, o que fica explícito pelas seleções lexicais "colocar ali o colchão, que muitas vezes ele ganha da própria sociedade civil” e "a sociedade pra não ofertar esse tipo de instrumental para ele se estabelecer na rua". Surge pela primeira vez o tema da "legalidade" das ações das pessoas em situação de rua com a disposição do "código de postura de município" como implícito pressuposto de limites para as pessoas em situação de rua. No sentido de uma estratégia que se articula para o controle do "lugar" (Certeau, 1998) rua, o código de postura de município retrata uma tentativa de definir limites de atuação dos indivíduos no uso dos bem públicos.

A rua como espaço habitado permite usos de todas as maneiras, inclusive pela criação de um espaço privilegiado de repouso, ou uma maloca, como fazem as pessoas em situação de rua. Embora, as malocas sejam proibidas pela prefeitura, elas existem, caracterizando táticas que burlam as estratégias de controle municipais. A forma de organizar e o controle legal das ações das pessoas de rua são formas de manter o poder estabelecido no lugar, manter a configuração estável dos elementos que trafegam ou fazem uso das ruas da cidade.

Há uma interdiscursividade entre as ações legais, prescritas e postuladas pelo município, representadas no léxico "o município tem que intervir" e o discurso da dignidade humana, somente possível para quem não está na rua, que implicitamente, é proporcionado pelo Estado para o povo, representada na seleção lexical "não podemos reconhecer o direito de viver na rua, viver na rua não é digno para ninguém". O enunciador atribui um papel suficiente às ações do estado, com amplo silenciamento sobre todo o resto. O enunciador ainda se coloca como personagem "não podemos", sujeito implícito "nós", de representação da política municipal e da hegemonia social institucionalizada pela posição que ocupa na secretaria. Sobre as condições sociais de produção do discurso, um aspecto relevante é o de que o enunciador fala de uma posição específica de dentro de um órgão da prefeitura, o que the confere legitimidade sobre o argumento hegemônico, e uma autoridade legal da qual ele se utiliza para conferir sentido de "bem comum" à sua fala. O enunciador do fragmento (003) se posiciona pelo discurso social institucionalizado nas políticas municipais. A fala que se refere a presidenta do Comitê de Acompanhamento e Monitoramento da Política Municipal para a População em Situação de Rua à época traduz o argumento legitimado pelas instanciais municipais de formulação de políticas sociais e se coloca como elemento de manutenção da ordem social frente as práticas das pessoas em situação de rua que insurgem contra essa ordem. Ao conferir o sentido de "bem comum" à sua fala, E3 assume uma impessoalidade que garante ao discurso um sentido de necessidade. 
Na seleção lexical "a área de fiscalização do governo junto com a área social" há um implícito subentendido de que o município e a sociedade convergem em seus interesses e, que o município age em nome da sociedade, fazendo valer a sua vontade pelo bem geral dos cidadãos. Entretanto, o cidadão de que falam as políticas públicas é um cidadão médio, para o qual o Estado propõe ações de interesse coletivo. Aqui cabe questionar: os interesses específicos da população em situação de rua seriam interesses compatíveis com os do cidadão "médio"? Aparentemente, não. As ações das pessoas em situação de rua são vigiadas e coibidas pela abordagem municipal, o que fica explicito na frase "você não pode fazer isso que ta fazendo aqui". A coerção se dá também explicitamente pela seleção lexical "vai recolher", com o tema da "intervenção municipal", indicando uma ação por parte da prefeitura de recolhimento dos pertences das pessoas ali estabelecidas. A refração linguística que fortalece o argumento de intervenção da prefeitura está na seleção lexical "viver na rua não é digno para ninguém". O principal aspecto ideológico defendido pelo discurso é o de que o Estado deve garantir a dignidade dos seus cidadãos, inclusive por meio da coerção de uns para beneficio de outros. $O$ argumento se fortalece pelo uso de uma perspectiva de "bem comum a todos", o que justifica a repressão dos desviantes. No âmbito das políticas sociais, a discussão necessariamente atinge todos os níveis que vão desde a intervenção mais acirrada ao amparo caritativo e assistencialista, embora quando evocada a força disciplinar do Estado, na figura da prefeitura, não haja dúvidas de que interessa a ordem social.

\section{Repressão policial e repressão social}

No fragmento (004) o enunciador traz aspectos da vida na cidade que se referem às repressões enfrentadas pela população em situação de rua. Repressão essa que deriva tanto da população domiciliada, comerciante, quanto da polícia, que representa a força coercitiva do Estado.

(004) A noite até que não, né? a noite, se você andar, você vai ver que tem muita gente que dorme, mas durante o dia é...tem uma certa intolerância em ficar nas marquises, que marquises são o que? Às vezes é porta de loja, aí o comerciante já pede para sair, né, são pontos comercias às vezes a própria polícia vem e pede para sair, né... A guarda municipal às vezes, por exemplo, praça da rodoviária é uma concentração muito grande de morador de rua, ele pode ficar lá, mas certamente se ele deitar lá certamente alguém vai pedir para ele não fazer isso... O parque municipal tem muitos moradores que durante o dia vai para o parque para pode dormir lá, se você for lá vai que eles deitam na grama, mas nem sempre é tolerado. Aqui então a gente não vê problema. (E6)

No fragmento (004) é possível identificar as ações de controle e monitoramento da cidade tanto pela ação do município pela coerção policial. O parque municipal, um espaço público da cidade, é local de descanso da população em situação de rua, embora isso não seja sempre tolerado. Um percurso semântico possível é o do "controle do espaço público" tanto pelas autoridades municipais legitimadas, como a polícia e a guarda municipal, quanto pela própria sociedade, no caso pelos comerciantes. Ambos não desejam que eles se estabeleçam nesses locais. Vários são os casos de retirada do espaço público. Com o diário de campo, podemos ilustrar alguns deles:

Quando chegaram, muitos estavam muito cansados e já encostaram em suas cadeiras, dormindo ali mesmo. Sentei-me entre eles e esperei. Logo chegou um rapaz mulato, de porte médio, que aparentava entre 25 e 30 anos. Ele tinha um corte de cabelo que parecia um desenho. Suas roupas eram bem melhor aparentadas do que a da maioria. Ele se sentou à minha frente e me perguntou quem eu era. Iniciamos uma conversa e logo ele relatou que na noite anterior havia sido expulso da frente da rodoviária por guardas do lugar. Disse que os guardas o chutaram enquanto dormia como se fosse um animal. Ele disse que isso era recente e que há pouco tempo eles começaram a tirar as pessoas de lá para não "queimar o filme da rodoviária". (Narrativa 06, PSR2)

Outro exemplo foi presenciado em uma das noites que passamos na rua:

Chegando lá, nos sentamos no chão da saída do metrô. Logo vieram dois guardas que nos questionaram se iríamos pegar o metro. A atitude deles era de desconfiança. Eles fizeram algumas perguntas e perceberam que nós não éramos pessoas em situação de rua. Mesmo porque um dos missionários explicou a eles o motivo de estarmos ali esperando. Eles retornaram a seus postos. (Registro do diário de campo)

A situação descrita não constitui uma expulsão, mas revela seu contínuo monitoramento, característica de uma estratégia de controle do espaço público. Outra característica nesse sentido são as citadas "arquiteturas antimendigo" citadas por Adorno e Varanda (2004, p. 65), e que compõem obstáculos diversos para que as pessoas em situação de rua não durmam sob as "marquises" ou em espaços públicos de uso monitorado pela prefeitura.

Os limites fugidios da população em situação de rua

Nos fragmentos (005) e (006) o enunciador fala sobre as possibilidades em que a força coercitiva da guarda municipal precisa ser ativada e argumenta que as pessoas de rua perdem os "limites", muitas vezes, infringindo as regras sociais de convivência na cidade.

(005) Então por que a guarda teve que vim para cá, porque tem hora que só a palavra não basta, tem que ter uma ação mais efetiva então a guarda tanto é... é... preventiva como determinado momento a gente precisa dela por exemplo não quer sair então a guarda tira do espaço... (E6)

(006) Também isso acontece quando eu te digo que a rua tira um pouco a noção de limite é nesse ponto de que às vezes a pessoa que está de baixo de uma marquise ela não pensa nessa coisa eu to aqui, mas eu não posso sujar aqui, eu to na rua, mas eu não posso defecar em qualquer lugar isso é uma coisa que a rua tira, então a gente aqui favorece para que essa pessoa encontre esses limites também, eu to na rua mas não posso fazer o que eu quero, não é porque eu to na rua que eu vou fazer um ato que vai infringir a regra da sociedade como um todo... (E6)

Nos fragmentos (005) e (006), o tema dos "limites" ressurge, implicando a necessidade de intervenção da guarda municipal. O percurso semântico da "coerção policial" possibilita uma leitura de "tem hora que a palavra não basta, tem que ter uma ação mais efetiva". Um interdiscurso presente nessa seleção lexical é o de que a guarda municipal sabe como agir efetivamente, garantindo eficácia na resolução do problema. A estratégia (Certeau, 1998), portanto, é a utilização da força coercitiva da guarda para estabelecer a ordem. Ora, a guarda municipal, tanto quanto a polícia militar, estão investidas de poder para impor a vontade do 
Estado, ou do município. Por isso, sua atuação dentro do centro de referencia é considerada "eficaz". A vontade estratégica se desenrola na imposição hierárquica que se tem sobre a população em situação de rua que, neste caso, compõe a parte que deve obedecer aos mandos da gestão. A questão da força para o cumprimento de normas é suavizada pelo emprego do verbo "favorecer". Só que isso cai quando o enunciador fala de "infringir a regra da sociedade como um todo", um tom normativo. No discurso do "limite", de que a "palavra" não ultrapassa em que a "coerção policial" é necessária, silencia-se sobre a formação da guarda municipal para lidar diretamente com essa população.

“Necessidades na porta da minha casa?”

No fragmento (007) é questionada a posição da sociedade em relação a formas das pessoas em situação de rua de fazerem suas necessidades. Também se trata da passagem do albergue da Pedreira Prado Lopes para o bairro Floresta.

(007) às vezes o pessoal da associação do bairro faz uma reunião e reclama, "ah porque o pessoal na hora que sai..." "ah esta tento assalto aqui em cima, ta tendo é...eles estão fazendo é... as necessidades na porta da minha casa" mas isso aí não é uma questão do bairro, do abrigo... Não to defendendo os usuários não, que eles aprontam mesmo...(E2)

No fragmento (007) surge o personagem da "associação do bairro" que reclama das ações dos usuários do albergue no entorno da organização. Surge o percurso do "controle do corpo", necessário socialmente, mas não pensado pelas políticas públicas. Não há banheiros nas ruas, tampouco nas praças e nos parques. $O$ enunciador combate a posição da sociedade civil de tentar impor tal controle. O discurso da "limpeza dos corpos" imprime um tom de moralidade às expectativas da sociedade em relação ao comportamento das pessoas em situação de rua, o que se manifesta pela tentativa de organização dos corpos, de limpeza da cidade e do afastamento do que é desagradável. Há ainda um interdiscurso entre o endereço anterior e o atual do abrigo, o que para o enunciador não faz diferença, já que se observa o mesmo comportamento independente do bairro, o que sugere que a sociedade precisa lidar com essa população no entorno do albergue. A resposta da sociedade, entretanto, parece ser a mesma nos dois lugares: um constrangimento explícito que questiona a existência do albergue, uma metonímia da própria população em situação de rua.

No âmbito das políticas sociais a ação da guarda municipal na lida com as pessoas em situação de rua, a discussão de provimentos para necessidades físicas dessa população e a organização e controle das condutas das pessoas de rua são constituídas de significados vários, debates e consolidados na atuação do Estado e da sociedade. O legitimo nem sempre é o mais agradável para aqueles que dependem das políticas, embora estejam os discursos, inclusive, da população em situação de rua, muitas vezes, em consonância com os significados aqui expostos.

\section{Discussão e Considerações finais}

A partir da constatação de que a população em situação de rua é uma questão social que precisa ser problematizada, nesse trabalho se buscou compreender como são articulados discursos que subsidiam as políticas sociais para a população em situação de rua na cidade de Belo Horizonte. A partir de uma pesquisa qualitativa com base em dados obtidos por meio de entrevistas semiestruturadas, observação participante e registro em diário de campo, foram obtidos subsídios para a abordagem da temática. Como é de se esperar em uma temática rica, multifacetada e polêmica como esta, muitas são as implicações possíveis.

Entendemos, com Fairclough (2001), que os significados extraídos nas falas constituem discursos que de forma intertextual estão presentes na formulação das políticas sociais em maior ou menor grau, especialmente, no contexto de políticas formuladas sob procedimentos mais democráticos. A legitimação da participação dos movimentos sociais, o MNPR, das entidades de apoio material e amparo religioso à população em situação de rua qualificam circunstancias em que a demarcação de objetivos de determinadas ações governamentais possam ser influenciadas pelos significados compartilhados por esses diferentes grupos e atores sociais. $\mathrm{O}$ caráter político e histórico da formação das políticas sociais para as pessoas em situação de rua, em suma, perpassa a participação das pessoas em situação de rua como atores e defensores dos seus direitos sociais garantidos constitucionalmente.

Nesse sentido, dentre as estratégias discursivas utilizadas pelos atores para persuadir o ouvinte em relação a seus argumentos, destacamos alguns significados que subsidiam as falas na expectativa de justificar as ações dos atores na lida com a população em situação de rua. Esses significados, reiteramos, não são apenas individuais, são compartilhados socialmente em determinados grupos e detém força política de atuação institucional segundo a posição dos atores que têm direito a fala nessas instâncias. Portanto, são forças argumentativas, que empreendem significados estrategicamente legitimados nos discursos, e subsidiam a formulação das políticas sociais seja em contextos democráticos, seja em contextos autoritários, tecnocráticos e de formulação política de gabinetes.

Dentre os significados destacados, temos i) o "controle das intenções", que evidencia uma relação direta entre o discurso do trabalho como elemento necessário à dignidade humana e o merecimento às políticas sociais, isto é, apenas aqueles que virem a cidade para trabalhar merecem apoio institucional, estabelecendo um interdiscurso com o discurso da meritocracia; ii) A tentativa de estigmatizar ou marginalizar a população em situação de rua nas falas, o que implica diretamente na possibilidade de ação política, reconhecimento de direitos e deveres dessa população, uma vez que o estigma "crackeados" implica um significado de inconsciência ou invalidez que caracteriza uma incapacidade de cuidar si; iii) o sentido da legalidade da vida nas ruas e a possibilidade de intervenção do Estado, ou do município, no sentido de uma coerção ao cidadão que assume conduta que implique em desvio da ordem social; iv) o "controle pela limpeza dos corpos" que implica a discussão de provimentos para necessidades físicas dessa 
população, sob resposta à necessidade de organização e controle das condutas das pessoas em sociedade.

Os significados destacados nos permitem inferir duas contribuições do artigo para a discussão da questão da população em situação de rua i) no âmbito aplicado a administração pública pela revisão dos significados atribuídos a população em situação de rua, nas instâncias de formulação de políticas sociais, enquanto grupo social e historicamente em luta por reconhecimento e realização dos seus diretos; ii) no âmbito teórico pela possibilidade de interlocução entre a discussão dos direitos sociais dos anônimos, nas palavras de Certeau (1998), e as práticas sociais dessa população enquanto resultado do seu posicionamento na estrutura social.

\section{Referências}

Adorno, R. C. F., \& Varanda W. (2004) Descartáveis urbanos: discutindo a complexidade da população de rua e o desafio para políticas de saúde. Saúde e Sociedade, 13(1), 23-45.

Albertsen N., \& Diken B. (2001) Mobility, justification, and the city. Nordic Journal Architectural Research, 14(1), 13-24.

Angrosino, M. (2009). Etnografia e observação participante. Porto Alegre: Artmed.

Decreto № 14.146 de 07 de outubro de 2010. (2015) Institui o Comitê de Monitoramento e Assessoramento da Política Municipal para a População em Situação de Rua, e dá outras providências. Belo Horizonte: Prefeitura de Belo Horizonte.

Decreto № 7.053 de 23 de dezembro de 2009. (2009) Institui a Política Nacional para a População em Situação de Rua e seu Comitê Intersetorial de Acompanhamento e Monitoramento, e dá outras providências. Brasília: Presidência da República.

Decreto s/n de 25 de outubro de 2006. (2008) Política Nacional para Inclusão Social da População em Situação de Rua. Brasília: Presidência da República. Bursztyn, M. (2003) No meio da rua: nômades, excluídos e viradores. Rio de Janeiro: Garamond.

Certeau, M. (1998) A invenção do cotidiano: artes de fazer. (Vol. 1, 3a ed.). Petrópolis: Vozes.

Chauí, M. (1989) Conformismo e resistência: aspectos da cultura popular no Brasil. (4a ed.). São Paulo: Brasiliense.

Costa, A. P. M. (2005) População em situação de rua: contextualização e caracterização. Revista Textos \& Contextos, 4(4), 1-15.

Fairclough, N. (2001) Discurso e mudança social. Brasília: Editora da Universidade de Brasília.

Ferreira, F. P. M. (2006) População em situação de rua, vidas privadas em espaços públicos: o caso de Belo Horizonte 1998-2005. Anais do Seminário sobre a Economia Mineira, Diamantina, MG, Brasil, 12.

\section{Notas}

'As noções de "texto" e de "discurso" são discutidas no tópico “Aspectos Metodológicos'
Ferreira, F. P. M., \& Machado, S. C. C. (2007) Vidas privadas em espaços públicos: os moradores de rua em Belo Horizonte. Serviço Social e Sociedade, 29(90), 1-20.

Ferreira, J. (2010) Tratar, cuidar: valores e práticas terapêuticas na assistência humanitária ao sans domicile fixe. Antropolítica, N 29, 79-97.

Fraser, N. (2007) Toward a nonculturalist sociology of culture: on class and status in globalizing capitalism. In: The Blackwell companion to the sociology of culture. Oxford: Blackwell.

Gaboriau, P. (2011) Sem domicílio em Paris, Moscou e Los Angeles um etnólogo em três campos de pesquisa: tentativas de esclarecimento. Antropolítica, N 29, 37-54.

Ghirardi, M. I. G., Lopes, S. R., Barros, D. D., \& Galvani, D. (2005) Vida na rua e cooperativismo: transitando pela produção de valores. Interface: Comunicação, Saúde e Educação, 9(18) 601-610.

Gonzalez Rey, F. (2005) Pesquisa qualitativa e subjetividade: os processos de construção da informação. São Paulo: Pioneira Thomson Learning.

Magni, C. T. (2010) Nova pobreza e paradoxos da política de inclusão social francesa: considerações a partir de uma oficina cerâmica no socorro católico. Antropolítica, N 29, 37-68.

Melo, T. H. A. G. (2015) População em situação de rua e "direito a ter direitos". Novos debates, 2(1), 198-206.

Mendes, L., \& Cavedon, N. R. (2012) A atividade de camelô como prática urbana no contexto das cidades. Urbe, 4(1), 123-140.

Mendes, M. V. B. (2007) Os moradores de rua e suas trajetórias: um estudo sobre os territórios existenciais da população de rua de Belo Horizonte.(Dissertação de Mestrado). Universidade Federal de Minas Gerais, Belo Horizonte, MG, Brasil.

Nardi, H. C., \& Rigoni, R. Q. (2005) Marginalidade ou cidadania? A rede discursiva que configura o trabalho dos redutores de danos. Psicologia em Estudo, 10(2), 273-282.

Neves, D. P. (2010) Habitantes de rua e vicissitudes do trabalho livre. Antropolítica, N 29, 99-130.

Resende, V. M. (2008) A naturalização da miséria contemporânea: análise discursiva crítica de uma circular de condomínio. Revista Brasileira de Linguística Aplicada, 8(1), 71-91.

Saraiva, L. A. S. (2009) Mercantilização da cultura e dinâmica simbólica local: a indústria cultural em Itabira (Tese de Doutorado). Universidade Federal de Minas Gerais, Belo Horizonte, MG, Brasil.

Silva, T. L. (2010) A rua como espaço de interação social: um estudo antropológico das relações entre população em situação de rua e grupos caritativos. Antropolítica, N 29, 131-149.

Silveira, D. X. da. (2013) Dependência não se resolve por decreto. Recuperado

de: http://www.uniad.org.br/index.php?view=article \&catid=29\%3 Adependen cia-quimicano ticias\&id=9364\%3Adeve-ser-permitida-a-internacaocompulsoria-de-viciados-emcrack\&form

at=pdf\&option=com_content\&ltemid= 94 .

Snow, D., \& Anderson, L. (1998) Desafortunados: um estudo sobre o povo da rua. Petrópolis: Vozes.

Vieira, M. C., Bezerra, E. M. R., Rosa, C. M. M. (Org.). (1994) População de rua: quem é? Como vive? Como é vista? São Paulo: Hucitec.

ii Grifos do autor. 